\title{
Case Report \\ Surgical Repositioning of an Inverted Developing Incisor Assisted by 3D Technology
}

\author{
Mi-Hyun Seo ${ }^{1,2}{ }^{\oplus}$, Hoon-Joo Yang ${ }^{1}{ }^{\circledR}$, Jeong-Joon Han ${ }^{1}$, Ik-Jae Kwon ${ }^{1}{ }^{\oplus}$, Hoon Myoung ${ }^{1}$ and \\ Soung-Min $\operatorname{Kim}^{1, *(D)}$ \\ 1 Department of Oral and Maxillofacial Surgery, Dental Research Institute, School of Dentistry, \\ Seoul National University, Seoul 03080, Korea; tjalgus@snu.ac.kr (M.-H.S.); yanghoonjoo@snu.ac.kr (H.-J.Y.); \\ oops01@snu.ac.kr (J.-J.H.); ijkwon@snu.ac.kr (I.-J.K.); myoungh@snu.ac.kr (H.M.) \\ 2 Department of One-Stop Specialty Center, Seoul National University Dental Hospital, Seoul 100-744, Korea \\ * Correspondence: smin5@snu.ac.kr; Tel.: +82-2-2072-0213; Fax: +82-2-766-4948
}

check for updates

Citation: Seo, M.-H.; Yang, H.-J.;

Han, J.-J.; Kwon, I.-J.; Myoung, H.; Kim, S.-M. Surgical Repositioning of an Inverted Developing Incisor Assisted by 3D Technology. Appl. Sci. 2021, 11, 4827. https://doi.org/ 10.3390/app11114827

Academic Editor: Guijun Bi

Received: 23 April 2021

Accepted: 20 May 2021

Published: 25 May 2021

Publisher's Note: MDPI stays neutral with regard to jurisdictional claims in published maps and institutional affiliations.

Copyright: (c) 2021 by the authors. Licensee MDPI, Basel, Switzerland. This article is an open access article distributed under the terms and conditions of the Creative Commons Attribution (CC BY) license (https:/ / creativecommons.org/licenses/by/ $4.0 /)$.

\begin{abstract}
Permanent central incisor impaction is very rare, and causes of impaction include adjacent supernumerary teeth, odontoma, and trauma. Surgical repositioning is a treatment option for teeth with ectopic eruption pathways. In this case report, an inverted developing maxillary central incisor was surgically repositioned at the initial stage of root development. Three dimensional (3D) virtual images were acquired using computed tomography, and a replica was produced by LCD-based masked stereolithography 3D printing. A resin for 3D printing was approved as a medical device and used as a 3D printing replica. Further, 3D technology has been found to be useful for successful tooth repositioning surgery.
\end{abstract}

Keywords: surgical reposition; 3D printing; central incisor impaction

\section{Introduction}

Impaction of a maxillary central incisor is rare, with a reported incidence of $0.06-0.2 \%$ [1]. Their related causes are adjacent supernumerary tooth, odontoma, trauma to deciduous teeth, root dilaceration, and space deficiency [2]. Displaced or reversely impacted incisors do not erupt spontaneously and cause restriction of root development. Space for an eruption is insufficient due to adjacent tooth movement [3]. Treatment of impacted central incisor with inverse location is challenging for clinicians. Surgical exposure followed by orthodontic traction is the most common treatment [4-6]. Surgical exposure with comprehensive orthodontic treatment requires an extended period of treatment. Despite the success of treatment, it can lead to unesthetic gingival tissue architecture [7]. Surgical repositioning of a tooth refers to the procedure in which an unerupted tooth is extruded surgically to its correct position by forming a new socket in the same alveolar bone [8]. If the developing maxillary permanent incisor is in an inverted position and at an early stage of root formation, surgical repositioning of a tooth is possible and might permit spontaneous eruption and root formation. Further, 3D technologies are widely used in the dental field: drilling or cutting guides in surgery, printing of maxillofacial implants, production of physical models for prosthodontics, orthodontics, and surgery, and fabrication of copings and frameworks for implant and dental restorations [9]. To create more predictable outcomes, we used computed tomography (CT)-guided surgical planning and the 3D printed tooth replica. The tooth replica was made using the LCD (liquid crystal display)-based masked stereolithography method. Mask stereolithography technology uses a LCD screen to create the mask, which creates the curing pattern [10]. The LCD machine is very cheap, and has good resolution [11]. In this study, we report on the usefulness of the 3D technique by successful repositioning surgery. 


\section{Case Report}

\subsection{Preoperative Evaluation and Preparation}

A 5-year-old male patient was referred from the department of pediatric dentistry for surgical extraction of an impacted mesiodens. A radiographic examination was performed including panorama, periapical view, and CT. The inverted mesiodens was impacted between the developing permanent maxillary central incisors. Three-dimensional (3D) CT imaging showed that the left maxillary central incisor was dislocated upside down and rotated buccopalatally (Figure 1).
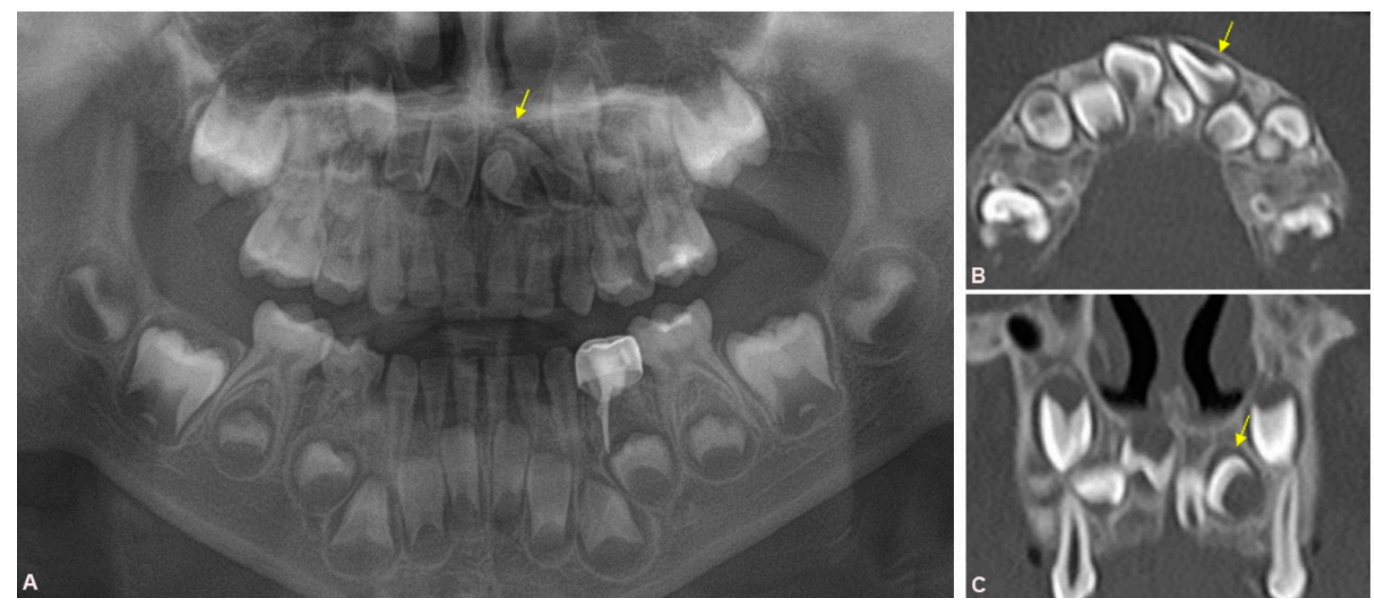

Figure 1. Preoperative X-ray, (A) Preoperative panoramic view shows the inverted mesiodens and maxillary central incisor impaction; (B) Axial view of computed tomography (CT) shows buccolingual inverted central incisor; (C) Coronal image of the CT, arrow: inverted central incisor.

The treatment plan consisted of extraction of the impacted mesiodens and repositioning of the displaced developing incisor in place. It was decided that a 3D simulation should be conducted prior to the actual surgery. Digital image files from the 3D CT were imported into Mimics ${ }^{\circledR} 19.0$ (Materialise, Leuven, Belgium). A 3D image file of the impacted developing permanent teeth was acquired (Figure 2A). The dislocated maxillary central incisor was moved into its original position in the virtual image (Figure 2B). It was confirmed that there was enough space between the adjacent embedding permanent teeth, and a bony interference was confirmed. The STL file was exported to CHITUBOX $64^{\circledR}$ (CBD-Tech, Shenzhen, China) for pre-processing of 3D printing (Figure 2C). All supports were set to a point size of $0.8 \mathrm{~mm}$, a density of $70 \%$. We set the printing layer thickness to $100 \mu \mathrm{m}$ and used a printing orientation of $45^{\circ}$. A rapid prototype model of the left maxillary developing central incisor was printed using a Phrozen Sonic Mini Desktop 3D printer $^{\circledR}$ (Phrozen Tech Co. LTD., Hsinchu, Taiwan). A commercial Bello C\&B Hybrid ${ }^{\circledR}$ (Bello 3D Co., Daejeon, Korea) resin was used to make the 3D printing replica. The support was removed with disc bur after printing. The replica was cured for 10 min using CureM U102H ${ }^{\circledR}$ UV LED post curing system (SONA GLOBAL Co., Ltd., Seoul, Korea) (Figure 2D). 
A
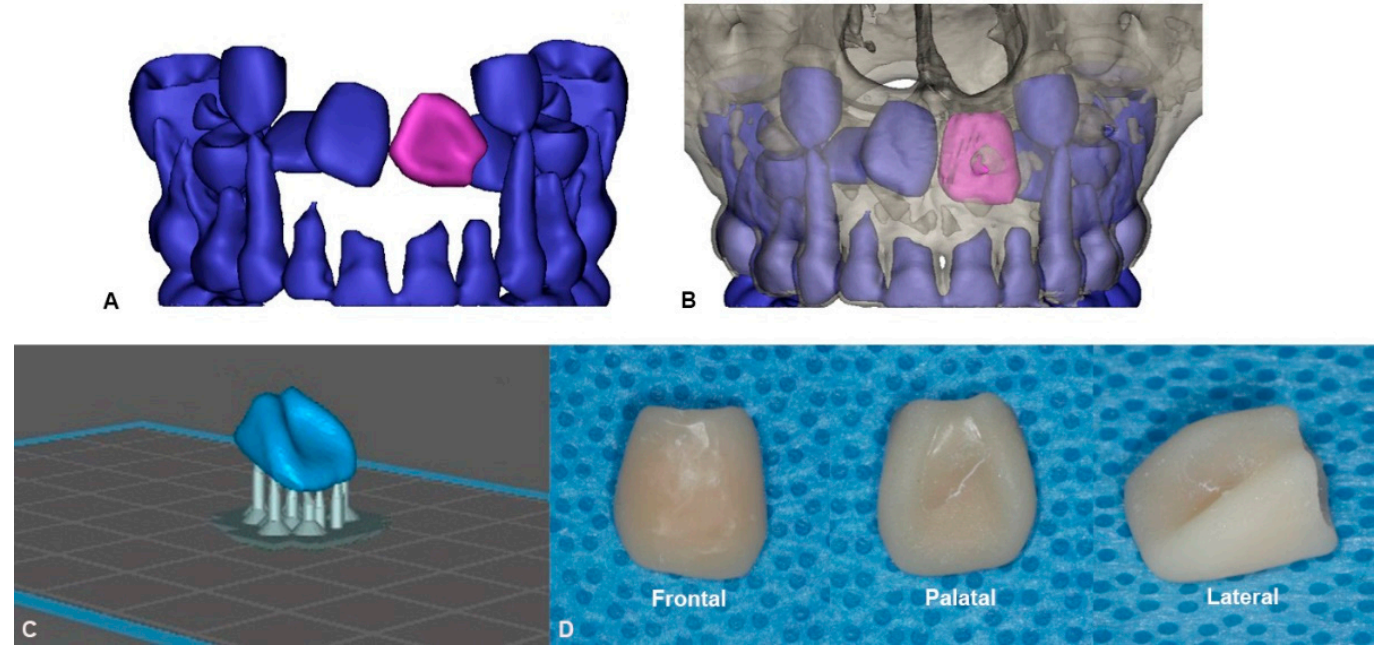

Figure 2. Virtual images of the central incisor, (A) Preoperative 3D image of the maxillary left central incisor (purple); (B) Images of the tooth (purple) moved to the planned position after surgery; (C) Images prepared for 3D printing using CHITUBOX $^{\circledR}$ (CBD-Tech, Shenzhen, China); (D) 3D printed replica views from various directions.

\subsection{Surgical Procedure and Follow-up}

The surgery was performed under general anesthesia. A crevicular incision was created on both the labial and palatal gingiva. A subperiosteal flap was elevated to expose the impacted teeth. The mesiodens placed in the palatal side of the deciduous maxillary central incisors was removed with a tooth elevator. A bony window was created on the labial side of the maxillary alveolar bone to expose the left maxillary central incisor (Figure 3A). The inverted impacted central incisor was rotated to the normal eruption pathway with dental forceps, and interfering bone was ground using the tooth replica (Figure 3B). In that way, we tried to minimize touching or damaging the actual tooth. The real tooth outside the socket was kept in wet gauze to prevent drying. The tooth follicle was preserved as much as possible, and the duration that the tooth was out of the socket was minimized. The transplanted tooth was placed in the ideal position, and the flap was closed with 4-0 Vicryl Rapide ${ }^{\circledR}$. The tooth position was maintained using a closed flap technique. The surgical splint was adapted to the maxilla. The actual operation time was 25 min including mesiodens extraction.
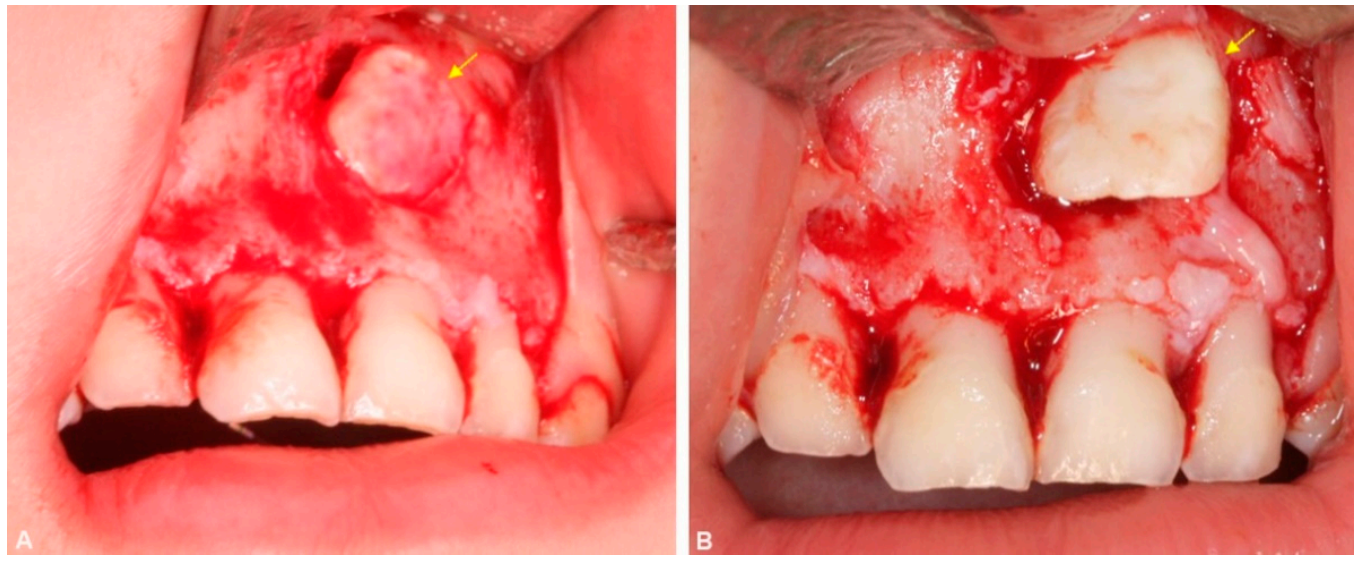

Figure 3. (A) Photo of the exposed tooth after overlying bone removal; (B) Photo of the repositioned tooth, arrow: developing central incisor.

A postoperative panorama was taken immediately after surgery, and the properly positioned incisor was identified (Figure 4A). Regular follow-up was conducted with 
panorama and periapical X-ray to observe root development and eruption of the embedded permanent tooth. At postoperative 3 months, the root development and normal periodontal healing was observed (Figure 4B, Table 1).
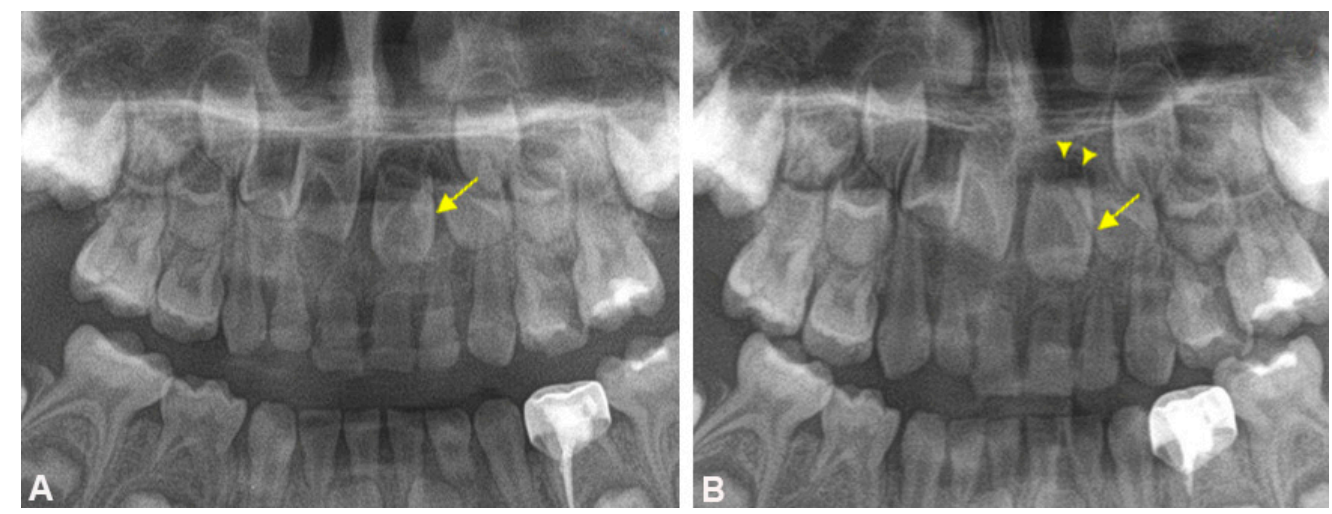

Figure 4. (A) Immediate postoperative panoramic view; (B) Postoperative 3 months panoramic view, arrow: repositioned central incisor, arrowhead: developing root.

Table 1. Postoperative results compared to preoperative condition.

\begin{tabular}{ccc}
\hline & Pre-op & Post-op \\
\hline Location of tooth & Inverted (malpositioned) & Forward (normal position) \\
Expectation for self eruption & Impossible & Possible \\
Related pathology & Possible & $\begin{array}{c}\text { Expected not to occur during } \\
\text { eruption }\end{array}$ \\
Root development & May be disturbed & Showed normal development \\
\hline
\end{tabular}

\section{Discussion}

The permanent central incisor can be impacted during the mixed dentition period. Calcification of the central incisor occurs at age 3 to 4 months and erupts at 6 to 9 years. Treatment of the impacted central incisor is important for facial esthetics [12].

Treatment options for impacted teeth with ectopic eruption pathways include surgical exposure and orthodontic traction, surgical repositioning, or extraction [13]. Determination of the treatment method is based on the position of the impacted tooth, its angulation, stage of root development, and presence of root dilaceration [14]. Forced eruptions have several issues such as long-term treatment, lack of attachment gingiva, and need for additional root canal therapy in dilacerated roots. Occasionally, forced eruption cannot be applied to cases of teeth that are too deeply impacted or exhibit complete vertical inversion. In that case, extraction may be considered but surgical repositioning can be selected as an alternative treatment option.

The advantage of surgical repositioning is that the tooth position can be corrected by a single surgical procedure. The mobilization of teeth in the intra-alveolar bone is easy in developing tooth germs. It has been reported that relocated tooth germs exhibit root development and normal eruption [4]. Treatment at the beginning of root growth redirects the Hertwig's epithelial root sheath, inducing the root to grow in the proper direction against the long axis of the crown, leading to normal root development [15]. Since the impacted tooth has growth potential even after early treatment, its root can continue to grow in a normal position [16]. However, damage to the tooth or adjacent surrounding tissues is unavoidable. For example, damage to the dental pulp, periodontal ligament, and Hertwig's epithelial root sheath can cause pulp necrosis, inflammatory or replacement resorption of the dental root, interruption of root development, and ankylosis [17]. In this respect, repositioning of the inversely impacted teeth to the forward direction at the early stage of root growth has the advantage of facilitating revascularization and inducing root 
growth in the correct direction. In this case report, we attempted to solve the issue of an inversely impacted central incisor at the same time as extraction of the supernumerary tooth. It was expected that root growth would be limited due to insufficient space for growth if only the supernumerary tooth was removed. We evaluated the positional interference relationship with the adjacent permanent developing teeth and obtained sufficient space for replantation by moving the tooth on the 3D virtual image obtained from the CBCT data before surgery. The tooth can be placed into the ideal position through the virtual surgery. In the actual surgery, the tooth was repositioned by removing the palatal bone so that the developing root could remain in the bony socket as much as possible. The actual tooth was wrapped in saline-soaked gauze to prevent drying. The tooth replica was used to remove bony interference on behalf of the real tooth. We made efforts to reduce the actual operation time by evaluating the amount and location of bone to be removed in advance. When replanting a tooth, the possibility of tooth damage may increase as the repetitive fitting and the time outside the socket increases. By simulating movements in advance before surgery, such repetitive tasks and time consumption can be reduced. We attempted to reduce tooth damage by minimizing manipulation of the real tooth using a $3 \mathrm{D}$ printed replica.

The commercial Bello C\&B Hybrid ${ }^{\circledR}$ resin is a biocompatible class Ila material (wavelength $405 \mathrm{~nm}$ ) for 3D printing the temporary crown and bridge. This material consists of urethane dimethacrylate (oligomer), trimethylolpropane trimethacrylate (monomer), metallic oxides (pigments). It may cause skin irritation, allergic skin reaction, and respiratory irritation. In the high vapor concentration, it may cause eye irritation. Although, LCDbased mask stereolithography is cheap, convenient, rapid, and a multifunctional technique in dental printing, limitations of light curable resin such as irritant, limited mechanical strength, lack of surface smoothness exist [18]. However, since the tooth replica was used in a short time during surgery, these disadvantages did not become an obstacle. It is possible to reduce ischemic time and surgical damage by minimizing the time that the tooth is located outside the socket with accurate preoperative planning. Three months after surgery, the tooth exhibited good healing (Figure 4B), but long-term follow ups are necessary.

\section{Conclusions}

Surgical repositioning of impacted teeth is a reliable treatment option. Virtual surgeries and 3D printed replicas are useful to reduce the operation time and surgical damage to the tooth germ. This method is useful not only for teeth having an ectopic eruption pathway, but also for transplanting teeth in other areas.

Author Contributions: M.-H.S.: writing the manuscript and acqusition of patient data, H.-J.Y.: designing of 3D work, J.-J.H.: revising and editing the manuscript, I.-J.K.: acqusition of patient data; H.M.: study design and revising the manuscript, S.-M.K.: drafting and revising the manuscript. All authors have read and agreed to the published version of the manuscript.

Funding: There is no funding related to this article.

Institutional Review Board Statement: The study was conducted according to the guidelines of the Declaration of Helsinki, and approved by the Institutional Review Board of Seoul National University (S-D20200011).

Informed Consent Statement: Written informed consent was obtained from patient's legal guardian for publication of this case report and accompanying images.

Data Availability Statement: Data sharing is not applicable to this article as no data sets were generated or analyzed during the current study.

Acknowledgments: This study was supported by grant no 03-2021-0045 from the SNUDH Research Fund.

Conflicts of Interest: The authors declare no conflict of interest. 


\section{References}

1. Grover, P.S.; Lorton, L. The incidence of unerupted permanent teeth and related clinical cases. Oral Surg. Oral Med. Oral Pathol. 1985, 59, 420-425. [CrossRef]

2. Huber, K.L.; Suri, L.; Taneja, P. Eruption Disturbances of the Maxillary Incisors:A Literature Review. J. Clin. Pediatr. Dent. 2008, 32, 221-230. [CrossRef]

3. Cozza, P.; Marino, A.; Ballanti, F. Orthodontic treatment of a patient with an unusual impaction of a central incisor: Case report. J. Dent. Child. 2003, 70, 174-177.

4. Kuroe, K.; Tomonari, H.; Soejima, K.; Maeda, A. Surgical repositioning of a developing maxillary permanent central incisor in a horizontal position: Spontaneous eruption and root formation. Eur. J. Orthod. 2005, 28, 206-209. [CrossRef] [PubMed]

5. Fllippi, A.; Pohl, Y.; Tekin, U. Transplantation of displaced and dilacerated anterior teeth. Dent. Traumatol. 1998, 14, 93-98. [CrossRef] [PubMed]

6. McNamara, T.; Woolfe, S.N.; McNamara, C.M. Orthodontic management of a dilacerated maxillary central incisor with an unusual sequela. J. Clin. Orthod 1998, 32, 293-297. [PubMed]

7. Tsai, T.P. Surgical repositioning of an impacted dilacerated incisor in mixed dentition. J. Am. Dent. Assoc. 2002, 133, 61-66. [CrossRef] [PubMed]

8. Saad, A.Y.; Abdellatief, E.-S.M. Surgical repositioning of unerupted anterior teeth. J. Endod. 1996, 22, 376-379. [CrossRef]

9. Dawood, A.; Marti Marti, B.; Sauret-Jackson, V.; Darwood, A. 3D printing in dentistry. Br. Dent. J. 2015, 219, 521-529. [CrossRef] [PubMed]

10. $\mathrm{Wu}, \mathrm{X} . ; \mathrm{Xu}, \mathrm{C} . ;$ Zhang, Z. Flexible film separation analysis of LCD based mask stereolithography. J. Mater. Process. Technol. 2021, 288, 116916. [CrossRef]

11. Quan, H.; Zhang, T.; Xu, H.; Luo, S.; Nie, J.; Zhu, X. Photo-curing 3D printing technique and its challenges. Bioact. Mater. 2020, 5, 110-115. [CrossRef]

12. Chaushu, S.; Dykstein, N.; Ben-Bassat, Y.; Becker, A. Periodontal Status of Impacted Maxillary Incisors Uncovered by 2 Different Surgical Techniques. J. Oral Maxillofac. Surg. 2009, 67, 120-124. [CrossRef]

13. Alberto, P.L. Surgical Exposure of Impacted Teeth. Oral Maxillofac. Surg. Clin. N. Am. 2020, 32, 561-570. [CrossRef]

14. Plakwicz, P.; Kapuścińska, A.; Kukuła, K.; Czochrowska, E.M. Pulp Revascularization after Repositioning of Impacted Incisor with a Dilacerated Root and a Detached Apex. J. Endod. 2015, 41, 974-979. [CrossRef] [PubMed]

15. Topouzelis, N.; Tsaousoglou, P.; Gofa, A. Management of root dilaceration of an impacted maxillary central incisor following orthodontic treatment: An unusual therapeutic outcome. Dent. Traumatol. 2010, 26, 521-526. [CrossRef] [PubMed]

16. Sun, H.; Hu, R.; Ren, M.; Lin, Y.; Wang, X.; Sun, C.; Wang, Y. The treatment timing of labial inversely impacted maxillary central incisors: A prospective study. Angle Orthod. 2016, 86, 768-774. [CrossRef] [PubMed]

17. Kim, S.; Kim, J.; Song, J.S.; Choi, H.-J.; Choi, B.-J.; Kim, S.-O. Continued root development of a surgically repositioned human incisor tooth germ. Oral Surg. Oral Med. Oral Pathol. Oral Radiol. 2013, 115, e11-e15. [CrossRef] [PubMed]

18. Khorsandi, D.; Fahimipour, A.; Abasian, P.; Saber, S.S.; Seyedi, M.; Ghanavati, S.; Ahmad, A.; De Stephanis, A.A.; Taghavinezhaddilami, F.; Leonova, A.; et al. 3D and 4D printing in dentistry and maxillofacial surgery: Printing techniques, materials, and applications. Acta Biomater. 2021, 122, 26-49. [CrossRef] [PubMed] 